\title{
Wolfgang Grunsky Gesetzesauslegung durch die Zivilgerichte im Dritten Reich
}

\author{
Dargestellt an Hand der in DR I939 Band 2, I940 Band I enthaltenen Recht- \\ sprechung*
}

I. In der klassischen Vorstellung einer strengen Aufteilung der den Staatsorganen zukommenden Macht zwischen der Exekutive, der Legislative und der Rechtsprechung hat letztere lediglich die Aufgabe, das Gesetz auf den zu entscheidenden Sachverhalt anzuwenden. Der Richter ist - wie Montesquieu es ausgedrüdst hat - la bouche de la loi^. Daß dieses Verständnis der richterlichen Tätigkeit den Dingen nicht gerecht wird, kann heute als gesicherte Erkenntnis gelten. In den wenigsten Fällen ist es so, daß der Richter als reiner Subsumtionsautomat fungiert. Im Rechtsprechungsakt ist vielmehr auch ein gutes Stïds bewußter oder unbewußter Wertentscheidung enthalten, die den Richter dazu führt, die Rechtsfolge a auszusprechen, obwohl der Wortlaut der angewendeten Norm es bei einer anderen Wertentscheidung genauso rechtfertigen würde, an den zu entscheidenden Sachverhalt die Rechtsfolge b zu knüpfen. Ganz klar wird dies bei den im Gesetz enthaltenen Generalklauseln ${ }^{2}$. Ob ein Verhalten mit Treu und Glauben vereinbar ist, ob es gegen die guten Sitten verstößt, oder ob es einen wichtigen Grund zur Kündigung eines Dauerrechtsverhältnisses darstellt, wird sich wohl nie mit letzter Sicherheit klären lassen. Es wäre jedoch ein Irrtum zu glauben, derartige $Z$ weifel könnten sich nur bei der Auslegung einiger weniger, vom Gesetzgeber bewußt unklar gehaltener Begriffe ergeben. Hier stellt sich die Problematik nur in besonders krasser Form, weshalb wir sie an anderer Stelle, wo es eines schärferen Zusehens bedarf, übersehen mögen. Dies kann aber nichts daran ändern, daß auch scheinbar so klar gefaßte Begriffe wie »Kind*, "Sache« oder "Grundstüds « auslegungsfähig und auslegungsbedürttig sind, wobei es dann häufig wieder von den Wertvorstellungen des Richters abhängt, für welche Auslegung - und damit für welche Rechtsfolge - er sich entscheidet. Oberspitzt gesagt läßt sich die Behauptung wagen, daß das Gesetz fast nur aus Generalklauseln besteht. Das bedeutet selbstverständlich nicht, daß das Gesetz abgedankt hat, und daß es nur noch vom Willen des Richters abhängt, wie er einen Fall entscheidet; es kann jedoch nicht verkannt werden, daß die Gerichte fast immer einen gewissen Spielraum haben, innerhalb dessen sich verschiedene Entscheidungen mit dem Gesetz vereinbaren lassen ${ }^{3}$.

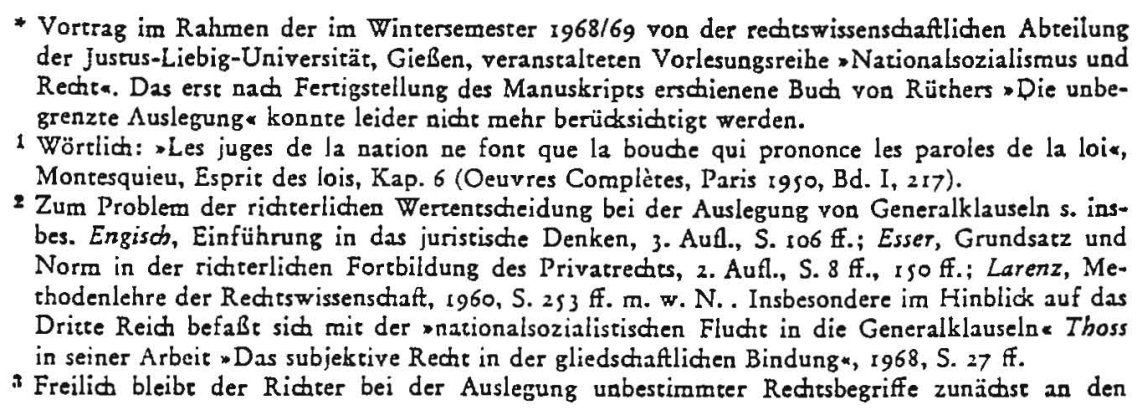


Dieser Befund legt es nahe; sich zu fragen, wie die Richter im Dritten Reich das Gesetz ausgelegt haben, was sie waus ihm gemacht haben . Haben sie das Geserz mir der Elle der national-sozialistischen Weltanschauung gemessen und dadurch Ergebnisse erlangt, die wir von unserem heutigen Verständnis her ablehnen müssen, oder haben sie umgekehrt versucht, die Offenheit eines jeden Gesezzeswortlautes dazu zu verwenden, in weitestmöglichem Umfang Resultate zu erreichen, die den Zielen des Nationalsozialismus widersprachen? Dieses Problem stellt sich naturgemäß für jeden Richter, für den Strafrichter also genauso wie für den Zivilrichter. Unsere Untersuchung beschränkt sich auf die Zivilrechtsprechung, was nicht besagen soll, daß die Dinge im Strafrecht notwendigerweise anders liegent. Im Rahmen des Zivilreches wollen wir uns jedoch nicht nur auf die Auslegung des bürgerlichen Gesetzbuchs und anderer weltanschaulich ungebunden scheinender Gesetze beschränken, sondern auch typisch nationalsozialistische Bestimmungen einbeziehen. Auch bei diesen stellt sich nämlich die Frage, inwieweit die Gerichte durch restriktive Auslegung versucht haben, die angeordneten ungerechten Rechtsfolgen nicht aussprechen zu müssen, oder ob sie nicht umgekehrt in den Fehler verfallen sind, das Gesetz auch auf solche Fälle anzuwenden, die vom Wortlaut der Norm her von dieser gar nicht erfaßt wurden.

Diese den Richtern an die Hand gegebene Möglichkeit, in ihrem engen Bereich als Bremse des Nationalsozialismus zu wirken, ist von diesem sehr schnell erkannt worden. Es fehlte denn auch nicht an Beeinflussungsversuchen, von denen die Präsidialbesprechungen und die Richterbriefe am bekanntesten geworden sind $^{5}$. Dabei wurde insbesondere versucht, den Ermessensspielraum bei der Auslegung von Generalklauseln dadurch einzuengen, daß vorgeschrieben wurde, diese Klauseln seien im Geiste des Nationalsozialismus zu interpretieren. Trotz dieser Versuche blieb der Rechtsprechung noch ein erheblicher Spieiraum, und zwar vor allen Dingen deshalb, weil auch die Interpretationsrichtlinien ihrerseits auslegungsbedürftig waren und damit Hintertüren offen ließen ${ }^{6}$. Eine Auslegung des Begriffs der guten Sitten führt auch dann nicht zu einem eindeutig allein richtigen Ergebnis, wenn ich den Geist des Nationalsozialismus mit heranziehe.

2. Vorab sind ein paar Bemerkungen zum Gegenstand und zur Methode der Untersuchung erforderlich. Es geht uns nicht um die Frage, ob und inwieweit Richter in dem Zeitraum von I933-1945 dem Nationalsozialismus offen die Ge-

Zweds des Gesezzes gebunden. Man kann Westermann darin folgen, daß Rechtsprechung darin bestehe, den festgestellten Tatbestand an Hand gesezzlich bindend festgelegter Faktoren wertend zu ordnen. (Interessenkollisionen und ihre richterliche Wertung bei den Sidherungsrechten «, 1954, S. 4). Fraglider erscheint jedoch die an anderer Stelle vertretene Ansidit Westermanns, Redisprechung sei dem Wesen nach Anwendung der gesezzlichen Wertungen im Gegensarz zur selbständigen Wertunge (Wesen und Grenzen der richterlichen Streitentscheidung im Zivilrecht, 1965, S. 21) - hier komme man der Vorstellung vom Mund des Gesetzes wieder gefährlich nahe.

- Mit Entscheidungen aus der Strafrechtspflege im Dritten Reich befaßt sidh besonders Scborn, Der Richter im Dritten Reich, 1959.

3 Zu den Lenkungsversuchen der Rechtsplege im Dritten Reich s. Ilse Staff, Justiz im Dritten Reid, 1964 , S. 68 ff. Eindrudesvolle Beispiele für Riditerbriefe sind bei Staff, a. 2. O., S. 69-98, Auszüge aus Protokollen der Präsidentenbesprechungen in Form von $\rightarrow$ Vor- und Nachschaubesprechungen innerhalb der Gerichte auf S. 99-104, Beispiele für Beeinflussungsversuche der Regierung über die Gerichespräsidenten und Generalstantsanwälte auf S. 104, 139 wiedergegeben. Zur Aushöhlung der sachlicten Unabhängigkeit der Rechespflege auch Wagner in $\rightarrow$ Die deursche Justiz und der Nationalsozialismus «, Bd. I, 1968, S. 208 ff.

- Weinkarff, Die deursche Jusriz und der Nationalsozialismus, Bd. 1, 1968, S. 92 ff. zeige die Schwierigkeiten auf, denen sich die Richter im Dritten Reich bei der Ausiegung von Generalklauseln gegenüber sahen: einerseits harten sie bei der Gesetzesauslegung die im Volke herrschenden allgemeinen Rechtsüberzeugungen und den geschichtlichen Wechsel der Wertvorsteilungen zu berücksichrigen, andrerseits aber war den Richtern großenteils die nationalsozialistische Ideologie fremd geblieben, so $\mathrm{daB}$ sie nicht aus einer echten Oberzeugung heraus ihren Entscheidungen nationalsozialistisches s Rechtsdenken zugrunde legten. 
folgschaft versagt haben, indem sie sich etwa weigerten, typisch nationalsozialistische Gesetze anzuwenden. Gegenstand dieser Untersuchung ist vielmehr die Frage, ob es eine Art hinhaltenden Widerstands gab, der sich darin äußert, daß man versucht, die Dinge so zu nehmen wie sie sind und das Beste daraus zu machen. Dabei ist es nicht nörig, daß sich der einzelne Richter bewußt gegen die Weltanschauung des Nationalsozialismus wendet; wir interessieren uns vielmehr auch für solche Fälle, in denen der Richter geglaubt haben mag, mit den Machthabern konform zu gehen, und sich im Ergebnis gleichwohl nicht aus der Tradition liberaler, religiöser oder sozialistischer Vorstellungen lösen konnte.

Wenn wir uns hier nicht mit dem offenen Widerstand beschäftigen wollen, so soll selbstverständlich nicht zu dem uralten Problem Stellung genommen werden, ob man dem Tyrannen auf die Gefahr hin offen zu widerstehen hat, daß man dabei zugrunde geht, ohne der guten Sache im Ergebnis einen Dienst erwiesen zu haben, oder ob es ethisch höherwertiger ist, pragmatisch zu denken und soweit irgend möglich $\mathrm{zu}$ helfen, was häufig nur um den Preis eines Paktierens und Sich-Vergleichens mit dem Bösen möglich ist. Uns geht es nur darum, was wirklich geschah und nicht, was vielleicht von einer Idealwarte aus gesehen hätte geschehen sollen.

Eine gründliche Untersuchung des so umrissenen Themas könnte nur auf Grund mehrjähriger Arbeit einer größeren Gruppe geleistet werden. Man müßte das unendlich umfangreiche Material (insbesondere alle noch vorhandenen Gerichtsakten) sichten. Eine derartige Untersuchung konnte bei der Vorbereitung dieses Vortrags nicht unternommen werden. Insbesondere war es nicht möglich, nicht veröffentlichte Entscheidungen durchzusehen. Die Ergebnisse stützen sich also nur auf Entscheidungen, die im Dritten Reich publiziert worden sind. Da auch dieses Material für eine gründliche Sichtung noch viel zu umfangreich isr, habe ich mich weiter darauf beschränkt, einen Jahrgang der größten juristischen Zeitschrift des Dritten Reichs, des Deutschen Rechts (Abk. $=D R$ ), zu analysieren. Dabei mußte natürlich versucht werden, einen einigermaßen typischen Jahrgang herauszugreifen, in dem der Nationalsozialismus einmal die Anlaufschwierigkeiten schon überwunden hatte, andrerseits aber auch noch nicht in den hysterischen Zudkungen des Untergangs lag. Ich habe mich für die zweite Hältte des Jahrgangs 1939 und die erste des Jahrgangs 1940 entschieden. In dieser Zeit hatte das Regime bereits Farbe bekannt (insbesondere waren schon die zahlreichen im November 1938 gegen die Juden erlassenen Vorschriften in Gelrung), ohne andererseits die bereits heraufziehende Katastrophe zu ahnen?

Ich bin mir darüber im klaren, daß gegen die praktizierte Auswahl des Materials Bedenken angemeldet werden können. Insbesondere müßten die Ergebnisse im Hinblick darauf überprü̈t werden, daß hier nur veröffentlichte Entscheidungen berüdksichtigt worden sind. Es spricht eine starke Vermutung dafür, daß das Gesamtbild günstiger ist, als es hier gezeichnet werden kann. Dies einmal deshalb, weil die Redaktion einer Zeitschrift seinerzeit natürlich eher geneigt war,

\footnotetext{
7 Weinkauff, a. a. O., S. 96 f. unterscheider verschiedene Phasen der Einwirkung des Nationalsozialismus auf die rechtsprechende Gewalr: $\pi$. Die Phase der revolutionären Umwälzung 1933-1934. 2. Die Phase der institurionellen Festigung des NS-Regimes 1935-1939 und 3. Die Radikalisierung der narionalsozialiscischen Einwirkung auf die Justiz während des Krieges 1939-1945 (Ara Gürener bis Januar 194I, Irs Schlegelberger bis August 1942, Ars Thierads bis Mai 1945). Die meisten der hier besprochenen Encscheidungen sind in dem Jahr vor und nach dem Kriegsbeginn ergangen. Weinkauff kennzeidner den Zeitraum vom Kriegsausbruch bis zum Tode des ersten Reidsjustizministers Dr. Gürmer (Januar 194I) als eine Periode der Scharfmacherei der Justizverwaltung und der strengen Oberwachung der Rechesprechung (S. I 34 ff.). Zu den kriegsbedingren Äaderungen im Verfahrensrecht $\nabla g l$. auch Wagner in $\rightarrow$ Die deutsche Justiz und der Nacionalsozialismus $\alpha$, Bd. I, S. 192 ff:
} 
linientreues Material zu veröffentlichen, als sich an gefährlichen Entscheidungen

die Finger zu verbrennen. Zum anderen muß berüdksidhtigt werden, daß Entscheidungen mit Ergebnissen, die geeignet waren, den Unwillen der Machthaber hervorzurufen, nur in den seltensten Fällen bis in die Redakrionsstuben gelangt sein dürften. Vermutlich hat das Gericht alles getan, um derartige Entscheidungen gar nicht erst publik werden zu lassen. Angesichts dessen ist es überraschend, daß sich unter den untersuchten Entscheidungen nicht nur unerfreuliche befinden, sondern fast in gleichem Maße solche, in denen es ohne weiteres möglich gewesen wäre, zu einem mit dem Nationalsozialismus besser übereinstimmenden Ergebnis zu gelangen.

3. Der untersuchte Jahrgang DR 1939, 2. Halbband und 1940, 1. Halbband enthält 38 Entscheidungen, in denen das Gericht entweder ideologische Vorstellungen des Nationalsozialismus verwirklichen wollte, ohne vom Gesetzeswortlaut her dazu gezwungen zu sein, oder in denen umgekehrt versucht wurde, derartige Vorstellungen abzuwehren. Dabei wurden solche Urteile nicht berücksictrigt, die (etwa wegen Fehlens eines Tatbestands) nur schwer einzuordnen sind. Gliedert man die Entscheidungen auf, so kommt man auf 21 unerfreuliche und auf I4 erfreuliche Entscheidungen. Die restlichen 3 Entscheidungen enthalten eine teilweise sehr weitgehende Auslegung weltanschaulich bedingter Gesetze, während auf der anderen Seite eben dieselben Gesetze eng interpretiert werden ${ }^{8}$. Im folgenden sollen einige besonders prägnante Beispiele dargestellt werden, wobei zunächst die unerfreulichen Fälle gebracht werden.

- Diese drei sowobl-als axcha-Entscheidungen sind: RAG DR 1940, 259 (Lohnfortzahlung nach Kündigung eines jüdischen Buchalters mindestens für eine Obergangszeit); RG DR 1940, ${ }_{367}$ (Ruhegehalt eines bereits früher ausgeschiedenen jüdischen Angestellten kann $z$ war nicht gestricien, aber herabgeserzt werden - vgl. unten Fall Nr. 6); OLG Breslau DR 1940, 577 (Scheidung einer Mischehe wegen des Rassenunterschiedes, aber Verschulden des sdeutsciblütigene Klägers aus Billigkeitsgründen); bei den sunerfreuliciene Urteilen bandelt es sidh in der Reibenfolge der Veröffentlichung um folgende: KG DR I939, 1384 (Beschwerderecht gegen Honorar eines jüdischen Rechesanwalts aus Nachlaßverwaltung); LG Bochura DR 1939, i46I (Prozeßkosten der obsiegenden Parrei, die durch Beauftragung eines emigrierten jüdischen Rechtsanwalts entstehen, sind nicht erstattungsfähig); RG DR 1939, 1569 (Irrtura über rassische Eigenschaften auch dann Eheaurhebungsgrund wenn zwar Kenntnis der Rassenzugehörigkeit bei Eheschließung vorlag, aber Wandel der Anschauungen erfolgt ist; KG DR 1939, is8; (Ein jüdischer Dritter, dern der Erblasser die Bestimmung des Testamentsvollstredkers überließ, hat kein Beschwerderechr gegen die vom Nachlaßgericht verfügte Emennung eines anderen Testamentsvollstredsers); LG Kleve DR 1939, 1818 (Kein Päctierschutz für einen Pächter, der ssich außerhalb der deutschen Voiksgemeinschaft gestellt hats, d. h. seine deutsche Stzatsangehörigkeit aufgegeben hatte); KG DR 1939, 1946 (Zusätzliche Erschwerung der Grundstüdksveräußerung eines emigrierten Juden durch strenge Formerfordernisse hinsidatlich der vormundschaftsgeridtclidhen Genehmigung); RAG DR 1939, 204I (Trotz des stärkeren Kündigungsschutzes für Lehrlinge kann Lehrlingsvertrag mit jüdischem Lehrling nach Treu und Glauben gekündige werden); KG DR 1939, 2 110 (Keine Anwendung der Verordnung zur Regelung der Fälligkeit alter Hypotheken vom 22. Dez. I938 - Schuldnerschutz!-auf jüdische Grundstüdkseigentümer); OLG Nürnberg DR 1940, 33 (Aufhebung einer Mischehe - vgl. unten Fall Nr. 3); KG DR 1940, 42 (Kein Grundstüdeserwerb eines Juden durch Abtretung eines Miterbenanteils); LAG Koblenz DR 1940, 87 (Kein Anspruch eines jüdischen Arbeiters auf Lohnzahlung an nationalen Feiertagen - vgl. unten Fall Nr. 2); AG Worms DR 1940, 295 (Reine Gehaltspfändung für jüdischen Gläubiger); KG DR 1940, 396 (Jüdischer Geschäftsraummieter ist nach $>$ Reichskristallnadit nicht zur Mietminderung berechtigt); KG DR 1940,459 (Eine GmbH gilt als jüdisch, wenn die jüdischen Gesellschafter Treuhänder eines A riers sind); KG DR 1940, 459 (Jude kann auch durch Erbauseinandersetzung keine Hypothek erwerben); AG Schöneberg DR 1940, 695 (Untersagung einer durch einen Juden betriebenen Zwangsräumung); KG DR 1940, 729 (Vorerbe kann kein Grundstüdesrecit erwerben, wenn zu den Nacherben ein Jude gehörz); KG DR 5940, $820 \mathrm{Nr} .38$ (Umwandlung einer auf dem Grundstück eines Juden lastenden Hypothek in Grundschuld ist genehmigungsptichtig); RAG DR 1940, 328 (Kündigung eines Angestellten aus wichtigem Grund, da Ehefrau in jüdischem Kaufhaus einkauft); ArbG Leipzig DR 1940, 830 (Kündigung eines Arbeitsverhältnisses wegen fehlender nationalsozialistischer Einstellung vgl. unten Fall Nr. I); KG DR 1940, 870 (Siedlungsvertrag kann wegen Ehe des Siedlers mit Jüdin gekündige werden); die folgenden Entscheidungen sind dagegen vom beutigen Standpunkt 
Im r. Fall (ArbG Leipzig, Urteil vom r 3. Febr. 1940, DR 40, 830) geht es um die Kündigung eines Arbeitsverhältnisses wegen fehlender nationalsozialistischer Einstellung einer Arbeitnehmerin:

Einer gehobenen Angestellten war - offenbar auf Drudk von NSDAP-Stellen hin - fristlos gekündigt worden. *Wichtiger Grund « für die fristlose Entlassung war ihre offen geäußerte antinationalsozialistische Einstellung. Die Angestellte, die im Betrieb die Stellung einer Unterführerin « innehatte, soll sich als arbeitgeberfreundliche Reaktionärin bezeichnet und erklärt haben, sie würde nie Nationalsozialistin. Im Betrieb war sie sonst als tüchtige Mitarbeiterin bei Kollegen und der GeschäAtsleitung beliebt. Die Klägerin focht nun vor dem Arbeitsgericht die Kündigung an, weil ihrer Ansicht nach kein »wichtiger Grund « im Sinne des $\$ 626 \mathrm{BGB}$ vorgelegen habe.

Nach h. M liegr ein wichtiger Grund, der nach $\$ 626$ BGB die Kündigung eines Dienstverhältnisses ohne Einhaltung einer Kündigungsfrist ermöglicht, dann vor, wenn »dem Kündigenden die Fortsetzung des Dienstverhältnisses und die Innehaltung der ordentlichen Kündigungsfrist nach verständigem Ermessen nicht mehr zugemutet werden kann $\alpha^{2}$. Es wird also lediglich darauf abgestellt, ob es zwischen dem Arbeirgeber und dem Arbeitnehmer zu Schwierigkeiten gekommen ist, was in dem zu entscheidenden Sachverhalt nicht der Fall war. Die klagende Arbeitnehmerin und der beklagte Arbeitgeber waren gut miteinander ausgekommen, womit es für das Gericht ein leichtes gewesen wäre, der Klage stattzugeben. Dennoch rechtfertigte das Arbeitsgericht Leipzig durch eine extensive Auslegung des $\$ 626$ BGB und durch Heranziehung des $\ 35$ des Gesetzes zur Ordnung der nationalen Arbeit vom 20. I. I934 (RGBl. I S. 45 ff.) diese *Drudkkü̈ndigung « ${ }^{10}$.

$\lceil 35$ des Gesetzes zur Ordnung der nationalen Arbeit lautet: »Jeder Angehörige der Betriebsgemeinschaft trägt die Verantwortung für die gewissenhafte Erfüllung der ihm nach seiner Stellung innerhalb der Betriebsgemeinschaft obliegenden Pflichten. Er hat sich durch sein Verhalten der Achtung würdig zu erweisen, die sich aus seiner Stellung in der Betriebsgemeinschaft ergibt. Insbesondere hat er im steten Bewußtsein seiner Verantwortung seine volle Kraft dem Dienst des Betriebes zu widmen und sich dem gemeinen Wohle unterzuordnen.*

Daraus folgert das Gericht, die Klägerin müsse in ihrer "Unterführerstellung"

aus ideologisch erfreulich: KG DR 1939,1386 (Arische Ehefrau eines verstorbenen Juden ist nur nicht befreite Vorerbin ihres nichtarischen Neffen); KG DR 1939, I394 (Hypothek auf einem wegen Zugehörigkeir zu kommunistischem Vermögen eingezogenen Grundstück erlischt nichs); KG DR 1939, I460 (Ist eine Hypothek vor dem gesezzlichen Erwerbsverbor an einen Juden abgetreten worden, so kommt es auf spätere Eintragung nicht mehr an); LG Berlin DR 1939, 1794 (Jüdischer Gesellschafter einer aufgelösten OHG kann als Abwidkler ins Handelsregister eingetragen werden); OLG Zweibrüdken DR 1940, III (Vertrag kann nicht angefochten werden, weil Vertragspartner Mischling zweiten Grades ist - vgl. unten Fall Nr. 5) RAG DR 1940, 133 (Verpflichtung des Geschättsnachfolgers zur Weiterzahlung eines Ruhegehalts an jüdischen Angestellten); RAG DR 1940, 516 (Unwirksamkeir einer Kündigung des Ruhegehalts, wenn sich der Ruhegehalesempfänger als Bibelforscher betätigt - vgl. unten Fall Nr. 4); RG DR 1940, 584 (Die Ehe eines Gesellschafters mit einer Jüdin ist kein Grund zur Ausschließung aus der OHG); KG DR 1940, 648 Nr. Is (Umwandlung einer Eigentümergrundschuld auf dem Grundstüds eines Juden in eine Hypothek zur Sicherung der Restkaufpreisschuld ist zulässig); RG DR 1940, 737 (Weiterzahlung von Ruhestandsbezügen an jüdischen Gemeindeangestellten); KG DR 1940, 820 (Grundstüdkserwerb eines Juden auf Grund testamentarischer Erbfolge zulässig); RAG DR 1940,876 (Keine ausdehnende Anwendung der Judengeserze auf Ruhegehaltsverpflictitungen gegenüber früheren Angesteliten); RG DR 1940, 106 (Formnichtigkeit einer Enclassungsverfügung auf Grund des Gesetzes zur Wiederherstellung des Berufsbeamtentums); OLG Hamburg DR 1940, 1069 (Klage auf Feststellung der arischen Abstammung gegen den unehelichen Vater auch noch nach dessen Tod).

- Bundesarbeirsgericht, Arbeirsrectrliche Praxis Nr. 16 zu $\$ 626$ BGB.

10 Zur Drudskündigung vgl. Hueck-Nipperdey, Grundriß des Arbeitsrectes, 2. Aufl., $§ 29$ V 3. 
den anderen nicht nur im Arbeitsleben und den Leistungen, sondern auch und gerade erst recht im Bereich der politischen Charakterbildung ein Vorbild sein. Da sie aber selbst erklärt habe, sie werde nie Nationalsozialistin, seien Erziehungsversuche an ihr unangebracht, so daß nur eine sofortige Entfernung weiteren Schaden für die Betriebsgemeinschaft verhüren könne. Auch wenn sie sich auf gutes Einvernehmen mit den Geschäftsführern oder Gesellschaftern berufe, so sei dennoch ein wichtiger Grund zur fristlosen Entlassung gegeben. Die Frage der Unzumutbarkeit einer Fortbeschäftigung könne wheute a nicht nur nach den individuellen Lust- und Unlustgefühlen eines kündigenden Betriebsführers, geschweige denn des hinter der beklagten $\mathrm{GmbH}$ stehenden Kapitals beurteilt werden, sondern einzig und allein danach, ob die Aufrechterhaltung des Arbeitsverhältnisses der Volksgesamtheit gegenüber verantwortet werden kann oder nicht. Auch auf ein harmonisches Zusammenarbeiten mit einem Teil der Gefolgschaft könne sich die Klägerin nicht berufen.

Wörtlich schließt das Urteil: »Selbst wenn in einem Betrieb $99 \%$ der Gefolgschaft staatsfeindlich eingestellt sind, würde die Frage, ob und inwieweit eine Kündigung gerechtfertigt ist, nicht vom Standpunkt dieser ziffermäßigen Mehrheit, sondern danach zu beurteilen sein, welche Entscheidung der gemeine volksbezogene Nutzen fordert. Dem gemeinen Nutzen von Volk und Staat aber entspricht es, daß eine Abteilungsleiterin, die ihre Unterführerstellung selbst in der Kriegszeit noch dazu mißbraucht, ihre reaktionäre und dem nationalsozialistischen Reich gegenüber feindliche Gesinnung und Einstellung bei passender Gelegenheit Ausdruck zu geben und dadurch wie ein Sprengstoff innerhalb der Betriebsgemeinschaft zu wirken, so schnell wie möglich entfernt wird. Die fristlose Entlassung erweist sich daher als begründet. *

Der 2. Fall (Urteil des Landesarbeitsgerichts Koblenz vom 4. August 1939 in DR r940, 87) beschäftigt sich mit der Frage, ob ein jüdischer Arbeiter an nationalen Feiertagen einen Anspruch auf Lohnzahlung hatze. Der Kläger war Jude und gegen Srundenlohn als Arbeiter bei der Beklagten beschäftigt. Er erhob Klage auf Lohnzahlung für den I. Mai und den 20. April 1939. Das Arbeitsgericht hatte der Klage stattgegeben, während sie vom LAG Koblenz abgewiesen wurde.

Die rechtliche Lage war wie folgt: Gemäß $\$ des Gesetzes über die Lohnzahlung am nationalen Feiertag des deurschen Volkes rom 26. April 1934 (RGBl I, 337) war den Arbeitgebern auferlegt, am I. Mai den Arbeitern trotz des Feiertages den regelmäßigen Arbeitsverdienst zu zahlen. Aus Anlaß des so. Geburtstages Adolf Hitlers wurde für den 20. April 1939 die gleiche Regelung getroffen ${ }^{11}$. Demnach hatten am 20. April 1939 und am I. Mai 1939 alle Arbeiter einen Anspruch auf Lohnzahlung, obwohl sie keine Arbeit leisteten. Da für jüdische Arbeiter keine Ausnahmeregelung getroffen worden war, nahm das in erster Instanz entscheidende Arbeitsgericht an, daß die entsprechenden Gesetze auch auf Juden Anwendung finden. Demgegenüber verneinte das Landesarbeitsgericht Koblenz für jüdische Arbeiter den Lohnanspruch mit folgender Begründung:

Die Bestimmungen über die Lohnfortzahlung an nationalen Feiertagen seien Ausnahmeregelungen von dem im Arbeitsrecht geltenden Grundsatz, daß nur tatsächlich geleistete Arbeit bezahlt wird. Diese Ausnahmebestimmung könne aber entsprechend ihrem $Z$ weck und dem Sinn der nationalen Sonderfeiertage keine Anwendung auf jüdische Arbeiter finden. Daß im Gesetz für jüdische Arbeiter die Lohnfortzahlung nicht ausdrücklich untersagt worden sei, sei ohne

11 .Gesetz über einmalige Sonderfeiertages vom 17. April 1939, RGBl I, 763 und die Durchführungsverordnung vom gleichen Tage, RGBl I, 763 . 
Bedeutung. Daraus lasse sich auf keinen Fall der Schluß ziehen, der Gesetzgeber habe die jüdischen Arbeiter ebenfalls begünstigen wollen. Der Gesetzgeber habe vielmehr nicht an die Anwendung auf Juden gedacht, weil es bisher im Wirtschaftsleben kaum jüdische Arbeiter gegeben habe. Deshalb könne nur eine *zweckentsprechende Auslegung * der einschlägigen Gesetze zur richtigen Entscheidung führen. $Z$ weck der Gesetze sei es vor allem, daß der deutsche Arbeiter an den Feierlichkeiten und politischen Veranstaltungen am 20. April und I. Mai teilnehmen könne, ohne von dem Gefühl eines Verdienstausfalls beschwert zu sein. Der jüdische Arbeiter habe aber an den nationalen Feiertagen weder äußeren noch inneren Anteil. Daher seien die Vorausserzungen, von denen diese Gesetze ausgingen, für ihn nicht zutreffend, woraus folge, daß die Vorschriften auf ihn nicht angewandt werden könnten.

Im 3. Fall (Urreil des OLG Nürnberg vom I4. Februar I939, DR 1930, 33) war zu entscheiden, ob ein arischer Ehemann Aufhebung seiner mit einer Jüdin seit langen Jahren bestehenden Ehe verlangen konnte. Die Ehe war am 9. Februar 1929 geschlossen worden. Der Kläger kannte von Anfang an die jüdische Abstammung seiner Frau. Dennoch stürzre er seine im Seprember 1938 erhobene Klage auf $\$ 37$ EheG vom 8. Juli I938 (RGBI I, 8II), der folgendermaßen lautet:

»I. Eine Ehegatte kann Aufhebung der Ehe begehren, wenn er sich bei der Eheschließung über solche die Person des anderen Ehegatten betreffenden Umstände geirrt hat, die ihn bei Kennenis der Sachlage und bei richtiger Würdigung des Wesens der Ehe von der Eingehung der Ehe abgehalten hätten.

2. Die Aufhebung ist ausgeschlossen, wenn der Ehegatte nach Entdeckung des Irrtums zu erkennen gegeben hat, daß er die Ehe fortserzen will, oder wenn sein Verlangen nach Aufhebung der Ehe mir Rücksichr auf die bisherige Gestaltung des ehelichen Lebens der Ehegatten sittlich nicht gerechtfertigt erscheint.\& Gemäß $\$ 4$ o EheG mußte die Klage innerhalb eines Jahres nach Entdedsung des Irrtums erhoben werden.

Das Oberlandesgericht Nürnberg gab der Aufhebungsklage statt: Den von $\ 37$ EheG vorausgesetzren *Irrtum bei der Eheschließung « über den Partner betreffende Umstände bejahte das Gericht, obwohl es selbstverständlich näher lag, ihn zu verneinen, womir die Klage abzuweisen gewesen wäre. Im einzelnen führt das Urteil aus:

$\S 37$ Abs. I des EheG sei weiter gefaßt ais der bis dahin einschlägige $\$ r 333 BGB. Dieser lautere:

"Eine Ehe kann von dem Ehegatten angefochten werden, der sich bei der Eheschließung in der Person des anderen Ehegatten oder über solche persönlichen Eigenschaften des anderen Ehegatten geirrt hat, die ihn bei Kenntnis der Sachlage und bei verständiger Würdigung des Wesens der Ehe von der Eingehung der Ehe abgehalten haben würde. $\times$

Anstatt des Irrtums über *persönliche Eigenschaften* sei jetzt maßgebend der Irrtum über $»$ Umstände, die die Person des anderen Ehegatten betreffen $\times . \mathrm{D}_{2}$ durch habe der Gesetzgeber nicht nur die Fälle des Irrtums über eine dauernde Beschaffenheit des Ehegatten (z. B. chronische, unheilbare Krankheit), sondern auch die, in denen eine immerwäbrende Dauer ungewiß ist, erfassen wollen.

Damit ist aber nach Ansicht des Gerichts die Bedeutung und der Umfang des neuen Geserzes nicht erschöpft: es sei jetzt ganz allgemein auf Umstände, die die Person des anderen Ehegatten betreffen, abzustellen. Solche Umstände könnten auch von außen kommende Ereignisse sein, z. B. neue gesetzliche Bestimmungen oder eine völlig veränderte Bewertung von bisherigen Tatsachen. Entscheidend 
sei nur, daß diese Umstände die Person des anderen Ehegatten betreffen und von solcher Bedeutung sind, daß sie einen Ehegatten bei Kenntnis dieser erst später eingerretenen Sachlage und bei richtiger Würdigung des Wesens der Ehe von der Eingehung der Ehe abgehalten hätten.

Bei einer so weiten Auslegung des Gesetzes hatte das Gericht keine Mühe mehr, die neue Bewertung des Rassenproblems als Umstände des Ehepartners, über die der Kläger geirr har, anzusehen: die Erkennenis des Rassenproblems habe sich erst seit 1933 dynamisch entwidkelt. Die Kenntnis der jüdischen Abstammung allein habe nicht genügt, wenn sie nicht in ihrer Bedeutung und Auswirkung erkannt wurde. Vor allem habe sich aber durch das Pariser Attentat vom 7. November r938 (Ermordung des deutschen Diplomaten vorn Rath durch den Juden Grynszpan) die Stellung des Judentums in Deutschland grundlegend geändert. Die Judenfrage sei durch das Pariser Attentat in ein ganz neues Stadium getreten. Durch die neuen Gesetze vom November r938 seien die Juden auch vom kulturellen und wirtschaftlichen Leben des Volkes ausgeschlossen worden. Diese Folgen seien neue Umstände i.S. des $₫ 37$ EheG, also Umstände, die in einet Mischehe die Person des jüdischen Ehegatten betreffen. Erst mit ihrem Eintritt sei der Irrtum über diese Umstände entdeckt gewesen.

Außerdem komme hinzu, daß die Entwidklung der Judenfrage die Eheleute schon seit längerem auseinander gebracht habe. Niemand habe ein Interesse an der Aufrechterhaltung dieser Ehe, weder die Parteien selbst, noch der Staat, noch die Volksgemeinschaft. Der Mann sei erst 34 Jahre alt, er könne eine arische Frau heiraten und von ihr arische Kinder bekommen. Die Frau erhalte ihre Selbständigkeit zurück und die Auswanderungsmöglichkeit werde ihr dadurch erleichtert. Kinder seien nicht vorhanden und Mischlinge, die künftig aus der Ehe hervorgehen könnten, seien durch die Fortsetzung der Ehe nicht erwünscht. Deshalb sei, wie es $\$ 37$ Abs. 2 EheG voraussetze, das Verlangen nach der Aufhebung der Ehe auch sitrlich gerechtfertigt'.

Den bisher besprochenen unerfreulichen Urteilen stehen einige mutige Entscheidungen gegenüber, in denen das Gericht zu Rechtsfolgen gelangte, die sicher nicht den Beifall der Machthaber fanden.

Im 4. Fall (Urteil des RAG vom 29. November I939 in DR I940, 3 r6) hatte das RAG die Frage zu entscheiden, ob einem Bibelforscher das Ruhegehalt entzogen werden konnte.

Der Kläger war von 1924 bis 1933 als Angestellter beim Deutschen Beamtenbund tätig. Als er 1933 ausscheiden mußte, wurde ihm eine Altersversorgung in Höhe von $40 \%$ seines letzten Gehaltes zugesprochen. Inzwischen wurde der Deutsche Beamtenbund in den Reichsbund der Deutschen Beamten, einen der NSDAP angeschlossenen Verband, umgewandelt. Der Beklagte Reichsbund war Rechtsnachfolger des Deutschen Beamtenbundes. Der Kläger war Mitglied der Vereinigung internationaler Bibelforscher, in der er auch nach ihrem Verbor illegal tätig war. Deshalb wurde er zu einer Gefängnisstrafe verurteilt. Nach Verbüßung der Strafe kündigte ihm der Reichsbund der Deutschen Beamten die Altersversorgung mit der Begründung, die Weiterzahlung könne ihm als einem der Partei angeschlossenen Verbande nach Treu und Glauben nicht zugemutet werden.

Es ging im Prozeß um die Frage, ob in der sog. "staatsfeindlichen Betätigung " eines früheren Angestellten des Rechtsvorgängers eines der NSDAP angeschlossenen Verbandes eine Treupflichtverletzung liegt, die zur Kündigung der Alters-

\footnotetext{
12 Ahnliche Entscheidungen zur Aufhebung von Mischehen nach $\int 37$ EheG sind auch veröffent-
} liche rom RG in DR 1939, 1569 und OLG München 1939, 327-5. Anm. 8. 
versorgung berechtigt. $\mathrm{DaB}$ eine Treupflichtverletzung den Arbeitgeber dazu berechtigen kann, das Ruhegehaltsversprechen zu widerrufen, war sowohl damals als auch heute noch ganz h. M. ${ }^{13}$. Damit handelte es sich nur noch um die Feststellung, ob die Tätigkeit des Klägers als Bibelforscher eine derartige Treupflichtverletzung darstellt. Es bedarf wohl keiner näheren Begründung dafür, daß es ein leichtes gewesen wäre, die Frage zu bejahen. Während sich die Vorinstanzen auf den Standpunkt des Reichsbundes der Beamten stellten, sprach das Reichsarbeitsgericht dem Bibelforscher die Altersversorgung in voller Höhe zu. Die Begründung läßt sich folgendermaßen zusammenfassen:

Grundsätzlich könne ein Ruhegehaltsversprechen nach der Pensionierung des Berechtigten nicht mehr gekündigt werden, da das Ruhegehalt eine nachträgliche Vergütung früher geleisteter Dienste darstelle. Eine entsprechende Anwendung des $\$ 626 \mathrm{BGB}$, der die fristlose Kündigung eines Dienstvertrages aus wichtigem Grund vorsieht, sei nicht möglich. $Z$ war bleibe der Ruhegehaltsempfänger auch nach der Pensionierung in einem gewissen Treupflichtverhältnis zum früheren Arbeitgeber. Bei schwerwiegenden Verstößen gegen diese Treupflicht sei die Geltendmachung eines Ruhegehaltsanspruchs mit Treu und Glauben nicht vereinbar. Aber diese Treupflicht bestehe grundsätzlich nur gegenüber dem früheren Schuldner, nicht aber demjenigen gegenüber, der als Rechtsnachfolger die Zahlungsverptlichtung übernommen habe (!). Gegenüber dem Rechtsnachfolger bestünde eine solche Verpflichtung nur, wenn dieser die ideellen und wirtschaftlichen Ziele des Rechtsvorgängers übernommen habe. Dieser Fall sei beim beklagten Reichsbund der deutschen Beamten nicht gegeben. Die Betätigung in der illegalen Vereinigung internationaler Bibelforscher richte sich ferner nicht gegen den Beklagten. Diese Betätigung berühre nicht die Beziehung zwischen dem Kläger und Beklagten und stelle daher keine Verletzung der Treupflicht dar.

Der beklagte Reichsbund berief sich weiter darauf, daß der Bibelforscher zwar nicht ihm gegenüber, wohl aber gegenüber Volk, Staat und Partei eine allgemeine Treupflicht verletzt habe. Bei der »staats- und volksfeindlichen Betätigung * des Klägers könne ihm, als einem der Partei angeschlossenen Verband, nichr zugemutet werden, ein Ruhegehalt zu bezahlen. Das Reichsarbeitsgericht weist auch diesen Einwand zurüdk: der Anspruch des Klägers sei ein einfacher vermögensrechtlicher Anspruch, der den gleichen Grundsätzen unterliege wie alle vermögensrechtlichen Ansprüche. Der Beklagte müsse diese Verpflichtung genauso erfüllen wie etwa die Zahlung des Kaufpreises für ein Grundstïdk. Die wegen einer Straftat gegen Volk, Staat und Partei Verurteilten stünden nicht außerhalb des bürgerlichen Rechts. $\mathrm{Ob}$ sie vermögensrechtliche Einbußen erleiden sollen, bestimme allein die staatliche Geserzgebung. Es bestehe kein Rechtssatz, daß private Schuldner aus einer strafgerichtlichen Verurteilung ihres Gläubigers Nutzen ziehen dürfen. Beamtenrechtliche Grundsätze, nach denen eine staatsfeindliche Betätigung des Ruhestandsbeamten zur Streichung der Altersversorgung führen könne, seien auf das vorliegende Angestelltenverhältnis auch nicht entsprechend anwendbar. Nach alledem sei der Reichsbund der Deutschen Beamten zur Weirerzahlung der Altersversorgung verpflichtet.

5. Fall: Wohl noch esfreulicher als das soeben geschilderte Urteil des RAG ist

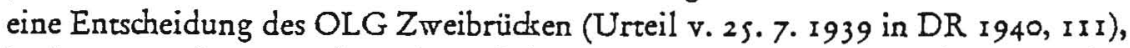
in der zu prüfen war, ob es ein Anfechtungsgrund i. S. des $\$$ I 19 Abs. 2 BGB ist, wenn ein arischer Vertragsparener nicht weiß, daß der andere Partner sog. Misch-

1s S. zuletzt BAG NJW I968, I445. 
ling zweiten Grades war. Der Kläger, ein Architekt, war vom Beklagten mir der Planung und dem Ausbau eines Weinlokales beauftragt worden. Nachdem die Pläne für die »Pfälzer Weinstuben « fertiggestellt waren, teilte der Beklagte dem Architekten mit, da dieser sogenannter Mischling zweiten Grades sei, könne er nicht mehr mit ihm zusammenarbeiten. Als der Kläger sein Honorar verlangte, berief sich der Beklagte darauf, daß er wegen seines Irrtums über die rassischen Eigenschaften des Architekten den Vertrag angefochten habe. Der Anspruch auf Zahlung des Honorars sei daher nicht entstanden. Es ging im Prozeß um die Rechtsfrage, ob die Irrtums-Anfechtung des Architektenvertrages durch den Bauherrn wirksam war. Dazu müßte sich der Bauherr

r. gemäß $\int$ IIg Abs. 2 BGB bei Abschluß des Vertrages im Irrtum über solche Eigenschaften der Person oder der Sache, die im Verkehr als wesentlich angesehen werden, befunden haben und

2. müßre anzunehmen sein, daß er seine Willenserklärung bei Kenntnis der Sachlage und bei verständiger Würdigung des Falles nicht abgegeben haben würde ( $I$ II Abs. I).

Die Wirksamkeit der Anfecttung hing also zunächst davon ab, ob die Tatsache, daß der beauftragte Architekt zu $25 \%$ nichtarischer Herkunft war, für den Vertrag über die Erbauung der $»$ Pfälzer Weinstuben« von verkehrswesentlicher Bedeutung war.

Eine sverkehrswesentliche Eigenschaft der Person\& i.S. des $\$$ II9 Abs. 2 BGB kann bei einem Architektenvertrag z. B. die Sachkunde und Zuverlässigkeir des Architekten $\operatorname{sein}^{14}$. Zu der im Dritten Reich akruellen Frage, ob auch die rassische Zugehörigkeir des Vertragspartners für den Architektenvertrag von wesentlicher Bedeutung ist, führte das OLG Z weibrüdsen folgendes aus:

Der Umstand, daß der Kläger Mischling zweiten Grades sei, sei keine wesentliche Eigenschaft i. S. des $\$ I I 9 Abs. 2 BGB. Der Mischling zweiten Grades könne dem Juden nicht gleichgestellt werden: aus einer Vielzahl von Vorschriften der Rassengesetzgebung lasse sich der Schluß ziehen, daß der Gesetzgeber bei der Unterscheidung $\mathrm{z}$ wischen Juden und Deurschen den Mischling $\mathrm{zweiten}$ Grades den Deutschen gleichstellen wollte. Er sei keinen wirtschaftlichen Beschränkungen unterworfen bis auf die Ausnahme, daß er vom Staat oder von Parteistellen keine Aufträge annehmen dürfe. Das sei aber auch die einzige Beschränkung seiner Berufsausübung. Von dieser Beschränkung sei der Bau eines Weinausschankes als eines rein privatwirtschaftlichen Geschäftes nicht erfaßt gewesen. Deshalb sei die rassische Zugehörigkeit des Architekten keine wesentliche Eigenschaft der Person i. S. des $\$ II 9 Abs. $z$ BGB. Außerdem fehle es an der zweiten Voraussetzung einer wirksamen Irrtumsanfechtung: nach Uberzeugung des Gerichts sei es dem Beklagten gar nicht entscheidend darauf angekommen, nur einen rein deutschen Architekten zu beauftragen. Deshalb sei anzunehmen, daß er den Auftrag auch erteilt bärte, wenn er die Mischlingseigenschaft des Klägers gekannt hätte. Der Klage des Architekten auf Zahlung des Honorars wurde somit stattgegeben.

6. Fall: Zum Abschluß soll ein Beispiel dafür gebracht werden, daß ein- und dasselbe Urteil ein rassisch bedingtes Geserz an einer Stelle unnötig weit auslegt, während es an anderer Stelle zu einer restriktiven Auslegung kommt. In dem Urreil des RG vom I2. November 1938 in DR 40, 367, ging es, wie in dem schon erwähnten Urteil des RAG (Fall 4), um den Verlust eines Ruhegeldes. Ein pensionierter kaufmännischer Angestellter jüdischer Herkunft, der fast sein

13 Vgl. Erman-Westermann, Handkommentar zum BGB, 4. Aufl. 1967, \$19 Anm. 9; PalandiDanckelmann, Kommentar zum BGB, 27. Aufl. 1968, Anm. 4 b. 
ganzes Leben in der beklagten Firma und zuletzt in leirender Stellung bis zum 3r. Mai 1932 tätig war, klagte auf Weiterzahlung seines Ruhegehalts. Sein Anspruch beruhte auf einem Pensionsvertrag, nach dem die Höhe des Ruhegehalts vom Jahre 1934 ab neu und nach billigem Ermessen bestimmt werden sollte.

Die beklagte Firma hatte die Zahlung eingestellt, da ihrer Ansicht nach auf Grund des $\$ 2$ Abs. 2 der „Verordnung zur Ausschaltung der Juden aus dem deutschen Wirtschaftsleben * vom 12. November 1938 der Ruhegehaltsanspruch des früheren Angestellten erloschen sei.

$\$ 2$ der Verordnung hat folgenden Worclaur:

r. "Ein Jude kann vom r. Januar 1939 ab nicht mehr Betriebsführer im Sinne des Gesetzes zur Ordnung der nationalen Arbeit vom 20. Januar 1934 sein.«

2. »Ist ein Jude als leitender Angestellter in einem Wirtschaftsunternehmen tätig, so kann ihm mit einer Frist von 6 Wochen gekündigt werden. Mit Ablauf der Kündigungsfrist erlöschen alle Ansprüche des Dienstverpflichteten aus dem gekündigten Vertrage, insbesondere auch Ansprüche auf Versorgungsbezüge und Abfindungen. *

Diese Bestimmung sagt also nichts über die Pensionsansprüche früher ausgeschiedener Angestellter aus, sondern versagt nur den Angestellten einen Pensionsanspruch, die auf Grund dieser Verordnung entlassen worden sind. Die Vorinstanzen hielten die Vorschrift daher hier für unanwendbar und hatten deshalb der Klage auf Weiterzahlung des Ruhegehaltes stattgegeben. Die beklagte Firma vertrat demgegenüber die Ansicht, daß, wenn schon den erst jetzt pensionierten leitenden Angestellten ein Ruhegehaltsanspruch vorenthalten werde, erst recht den früheren Angestellten die Pension entzogen werden müsse. Dieser extensiven Auslegung zuungunsten des jüdischen Klägers folgte das RG nicht: Nach ihrem Wortlaut biete die VO nur die Möglicheir, noch im Dienst befindliche jüdische Angestellte ohne Pensions- oder Abfindungsansprüche auszuschalten. Es sei zwar auch die entsprechende Anwendung auf solche Fälle zu vertreten, in denen Juden bereits früher infolge der politischen Entwidklung aus leitenden Stellungen ausscheiden mußten. Diese Voraussetzungen träfen aber für den schon im Mai 1932 pensionierten Kläger nicht zu.

Man müsse den zweiten Absatz des $\$ 2$ der Verordnung zur Ausschaltung der Juden im engen Zusammenhang mit dem ersten Absatz lesen. Da nach Abs. I die Unternehmen jüdische Betriebsführer entlassen mußten, wäre es eine nicht zu rechtfertigende Härte gewesen, sie an einer etwa eingegangenen Verpllichtung zur Zahlung von Versorgungsbezügen und Abfindungen festzuhalten. Dieser Grund falle aber fort, wenn der jüdische leitende Angestellte schon vorher auf Grund einer Vereinbarung ausgeschieden sei und das gelte ganz besonders, wenn, wie hier, für das Ausscheiden die politische Entwicklung nicht maßgebend war. Deshalb lasse sich aus der *VO zur Ausschaltung der Juden aus der deutschen Wirtschaft* der Wegfall der Ruhegehaltsansprüche des Klägers unmittelbar und für sich allein nicht begründen. Das RG spricht dem Kläger das Ruhegehalt aber nicht in voller Höhe $\mathrm{zu}$, was man nach den bisherigen Ausführungen eigentlich hätte erwarten können. Das Urteil meint vielmehr, in der *VO zur Ausschaltung der Juden aus der deutschen Wirtschaft« komme ebenso wie in anderen rassepolitischen Gesetzen der Grundgedanke einer möglichst vollständigen Ausschaltung des jüdischen Einflusses zum Ausdrudk. Hinter diesem von der Gesetzgebung verfolgten $Z$ weds müßten die privaten Ansprüche des einzelnen Juden, vor allem auch seine Ruhegehaltsansprüche, dann zurüdstreten, wenn einem Unternehmen infolge der *Entjudung * des Betriebes nicht zumutbare Opfer zugemuter würden. Dieser Gedanke sei auch für die Beurteilung dieses Falles relevant, wenn, 
wie hier, nach dem Pensionsvertrag über die Höhe des Ruhegehalts unter Berüdksichtigung der Gesamtumstände nach billigem Ermessen entschieden werden solle. Es widerspreche dem Willen des Gesetzgebers und dem gesunden Volksempfinden, wenn man das Ruhegehalt eines früher ausgeschiedenen Juden zu hoch ansetze. Damit nähme der Jude an einer Aufwärtsentwidklung des verpflichteten Unternehmens teil, die nicht sein Verdienst, sondern eine Folge des allgemeinen, durch die nationalsozialistische Wirtschaftsführung hervorgerufenen Aufschwungs sei. Der Ruhegehaltsanspruch des jüdischen Klägers sei daher herabzusetzen ${ }^{15}$.

4. Damit sind wir mit der Darstellung von Einzelfällen am Ende und müssen versuchen, ein Fazit aus dem verarbeiteten Material zu ziehen. Wollen wir bei der Bewertung der Zivilrechtsprechung im Dritten Reich nicht ungerecht verfahren, so müssen wir eine deutliche Trennung zwischen eindeutigen Unrechtsurteilen und solchen Entscheidungen vornehmen, die zwar auf einer Wertung des Richters beruhen, die wir heute nicht mehr anerkennen können, die sich jedoch nicht als Unrecht abstempeln läßt. Leider wird die Norwendigkeit einer solchen Differenzierung heute nicht immer hinreichend beachtet.

Wir haben bereits gesehen, daß jede Gesetzesauslegung eine Wertung beinhaltet, die dem Gesetz selbst nicht entnommen werden kann, sondern vom Auslegenden bei der Fallentscheidung ins Spiel gebracht wird. Dies bedeuter, daß ein richterliches Urteil in der Regel nicht bis in die letzten Verästelungen der Begründung einer streng rationalen Kritik standhält. Damit soll nicht gesagt sein, daß die Rechtswissenschaft sich nicht mehr darum bemühen sollte, verstandesmäßig nachvollziehbare Entscheidungen zu treffen, sondern lediglich, daß wir die in der Natur der Dinge liegenden Grenzen eines rationalen Argumentierens anerkennen müssen. Man mag es beklagen, daß uns derartige Grenzen gesetzt sind - ich selbst würde in diese Klage übrigens nicht einstimmen -, doch vermag dies nichts an den Realitäten zu ändern. Es gibr keine Gesetzesauslegung ohne Verwendung von Wertvorstellungen ${ }^{16}$. Wie weit auch wir heute von einer strengen Rationalität entfernt sind, darf ich an einem Beispiel aus der Rechtsprechung des BAG (AP Arr. 6 Abs. I GG Nr. I) darlegen. Ich habe dabei bewußt einen Fall gewählt, der überwiegend auf Zustimmung stoßen wird. Dies soll aufzeigen, daß es in der Auseinandersetzung mit dem Dritten Reich weniger um ein Gegenüber von Rationalität und Irrationalität, als vielmehr von zwei Weltanschauungen geht, von denen sich keine als richtig »beweisen * läßt.

Das Bundesarbeitsgericht hatte zu entscheiden, ob einer noch in der Ausbildung befindlichen Krankenpllegerin mit der Begründung gekündigt werden konnte, sie habe geheiratet. Der Arbeitsvertrag sah ein Erlöschen des Arbeitsverhältnisses für den Fall einer Eheschließung vor. Das BAG erklärte diese Klausel für nichtig, da sie insbesondere gegen Art. 6 Abs. I GG verstoße, und die Kündigung infolgedessen für rechtswidrig. Dabei hatte sich das Gericht zunächst mit der umstrittenen Frage auseinanderzusetzen, ob die Grundrechte, die an sich die Freiheitssphäre des einzelnen vor Eingriffen der Staatsgewalt sichern sollen, auch unmittelbar für den Privatrechtsverkehr verbindlich sind. Diese sog. Drittwirkung der Grundrechre ${ }^{17}$ bejaht das BAG, wobei es u. a. im Urteil heißt:

15 Die Anwendung des $\oint_{2}$ Abs. 2 VO zur Ausschaltung der Juden aus dem deurschen Wirtschaftsieben auf bereits pensionierte Rubegehaltsempfänger hat das RAG in DR 40,876 noch dezidierter als das RG abgelehne; vgl. Anm. 8.

$18 \mathrm{Vgl}$. dazu oben bei Anm. 2 und 3 sowie allgemein zur Aufgabe der Rechtsphilosophie bei der Auffindung der Wertvorstellungen Radbruch, Rechtsphilosophie, s. Aufl, S. 97 ff., insbes. $102 \mathrm{ff}$. (* Wertrelativismusa).

17 Ausführlich zur Problematik der $>$ Drittwirkung der Grundrechte» vgl. Maunz-Dürig, Kommentar zum Grundgeserz, Art. I Rdnr. $127 \mathrm{ff}$. 
*Die Grundrechte sind Ordnungsgrundsätze für das soziale Leben, die unmittelbare Bedeurung auch für den privaten Rechtsverkehr der Bürger untereinander haben. Sie sind das Ordnungsgefüge, der ordre public einer konkreten Staatsund Rechtsordnung. Auch das normarive Bekenntnis des Grundgesetzes zum sozialen Rechtsstaat spricht für die unmittelbare privatrechtliche Wirkung der grundrechtlichen Bestimmungen, die für den Verkehr der Rechtsgenossen untereinander in einer freiheirlichen und sozialen Gemeinschaft unentbehrlich sind. * Aber auch bei der Anwendung einzelner Grundrechte auf den vorliegenden Fail kann man über die daraus herzuleitenden konkreten Rechrsfolgen verschiedener Ansicht sein. Die vom BAG ausgesprochene Nichtigkeit des vereinbarten $*$ Eheverbots« schränkt nämlich die Vertragsfreiheit ein, die nach h. $M$ ebenfalls vom GG - und zwar durch die in Art. 2 Abs. I garantierte freie Entfaltung der Persönlichkeit - geschürzt wird ${ }^{18}$. Das Urteil räumt zwar ein, daß die Parteien eines Arbeitsvertrages berechtigt sind, den Inhalt ihres Vertrages selbst zu bestimmen und auch das Ende des Vertrages von Bedingungen abhängig zu machen, die Vertragsfreiheit gelte jedoch nur innerhalb der verfassungsmäßigen Ordnung. Sie finde ihre Grenze in den Vorschriften der Verfassung, die ein böberwertiges Rechrsgur gewährleisten wollten. Hierzu gehöre die in Art. 6 Abs. I geschützte Ehe.

Diese Auffassung vom Vorrang des Rechts auf Eingehung einer Ehe vor der Vertragsfreiheit begründet das Gericht u. a. mit Feststeilungen wie odie Eheschließung ist ein höchstpersönliches Rechtsgeschäft, das von jedem Zwang frei sein muß. Die Eingehung der Ehe soll allein dem freien sittlichen Entschluß der Partner unterliegen. Durch die Vereinbarung einer Zölibatsklausel wird dies verhindert, denn der Arbeitnehmer wird vor die Wahl gestellt, entweder unter Aufgabe seines Arbeitsplatzes zu heiraten oder auf die Eingehung der Ehe zu verzichten. In vielen Fällen kann heute nur geheiratet werden, wenn die Ehefrau mitverdient, ja es gibt sogar Fälle, in denen die Ehefrau allein die neu zu gründende Familie ernähren muß, wie etwa bei der Eingehung einer Ehe mit einem noch nicht arrivierten Künstler oder Studenten. Die Zölibatsklausel würde sich also zuungunsten sozial schwacher oder hilfsbedürftiger Personen auswirken und dazu führen, daß entweder die Eingehung der Ehe verhindert oder die Arbeitnehmer zu sog. >wilden Ehen

Deshalb verstoße die Zölibarsklausel nicht nur gegen Art. 6 Abs. I, sondern auch gegen Art. I Abs. I GG, der die Würde des Menschen für unantastbar erklärt. Der Schutz der Menschenwürde sei seine verbindliche Wertentscheidung für die gesamte Rechtsordnung «.

Wörtlich meint das Gericht weiter: »Soll die Würde des Menschen die Grundlage unserer Rechtsordnung sein, so muß Art. I Abs. I nicht nur für den Staat Richtschnur seines Handelns sein, sondern muß er von jedem Bürger geachtet und darf er von ihm nicht verletzt werden. Rechtsgeschäfte verstoßen dann gegen Art. I Abs. I GG, wenn sie zu einer Handlung oder einer Unterlassung verpflichten sollen, die im Interesse der Würde des Menschen völlig frei sein soll. Die Würde des Menschen erfordert es, daß er selbst darüber entscheiden kann, wie er sein Leben gestaltet, insbesondere also, ob er heiratet. *

$\mathrm{Da}$ durch die Zölibarsklauseln ein indirekter $Z$ wang auf den Heiratswilligen ausgeübt werde, verstoßen sie nach Ansicht des Gerichts gegen die Menschenwürde genauso wie gegen die von Art. 2 Abs. I gewährleistete freie Entfaltung der Persönlichkeit, denn, so meint das BAG, sgerade das Recht zur Eheschließung ist ein

18 Hicrzu Hamann, GG, Art. 2 Anm. C 3; Maunz-Dürig 2. 2. O., Art. 2 Abs. I Rdnr. 53 ff., der sich insbesondere in Rdnr. 57 gegen dieses Urteil wendet. 
wesentlicher Bestandteil des Rechtes zur freien Entfaltung der Persönlichkeit. Kaum ist ein weitergehender Eingriff in die Freiheit der Persönlichkeit denkbar, als wenn ein Mensch zur Ehe gezwungen oder wenn der Abschluß der Ehe verboten oder erschwert würde.\&

Es bedarf wohl keiner weiteren Darlegung, daß das BAG sein sicher begrüßenswertes Ergebnis nicht durch streng rationale Deduktion, sondern in erster Iinie durch bewußre Wertung der einander gegenüberstehenden Lösungsmöglichkeiten gewonnen hat.

Die bei der Gesetzesauslegung verwendeten Wertvorstellungen haben nun die Eigenschaft, sich im Laufe der Zeit zu verändern, und zwar sowohl in der Person des einzelnen Gesetzesinterpreten als auch innerhalb größerer Gemeinschaften. Was gestern als richtig empfunden wurde, kann von uns heute abgelehnt werden, und unsere derzeitige Weltanschauung findet vielleicht nicht die Billigung der Generation von morgen. Dabei ist wichtig, daß innerhalb eines gewissen Rahmens keine Weltanschauung für sich in Anspruch nehmen kann, sie sei höherwertiger als andere. Ich sage: innerhalb eines gewissen Rahmens. Es ist selbstverständlich, daß sich die Ausrottung der Juden oder auch nur ihre vermögensrechtliche Benachteiligung nicht durch Berufung auf eine Weltanschauung rechtfertigen läßt. Wenn dagegen im Dritten Reich und häufig auch in seiner Rechtsprechung der Wert der Nation oder eines bodenständigen Bauerntums in einer uns nicht mehr nachvollziehbaren Weise überbetont wird, so wird damit der Rahmen noch nicht gesprengt. Hier bewegen wir uns im Bereich des noch Vertretbaren.

Für unser Thema ist all dies deshalb wichtig, weil wir uns davor hüten müssen, jedes Urteil, das auf derartigen noch vertretbaren, wenn auch von uns nicht mehr geteilten Wertvorstellungen beruht, zum Unrechtsurteil zu erklären ${ }^{19}$. Ein Richter, der im Bereich des Landwirtschaftsrechts vielleicht zu stark Vorstellungen verwirklichen wollte, die wir nicht zu teilen vermögen, konnte sehr wohl versuchen, typisch rassisch bedingte Gesetze durch eine enge Auslegung soweit irgend möglich zu entschärfen. Uns geht es nicht darum, Urteile zu bewerten, bei denen Rechtsfragen zu entscheiden waren, deren Antwort auf jeden Fall nicht aus dem Rahmen des noch Vertretbaren fällt. Wir interessieren uns vielmehr nur für solche Entscheidungen, in denen der Richter entweder selbst die Grenze eindeutig überschritten hat, oder gezwungen war, sich mit Grenzüberschreitungen des Gesetzgebers auseinanderzusetzen, und nur solche Entscheidungen sind auch berücksichtigt worden.

s. Kommen wir zum Schluß. Nach dem Gesagten dürfte klar sein, daß sich kein extremes Ergebnis vertreten läßt. Weder geht es an, die Rechesprechung im Dritten Reich als gefügige Dienerin des Nationalsozialismus anzusehen, deren höchstes Streben danach ging, ihrem Herren in weitestmöglichem Umfang zu Diensten zu sein ${ }^{20}$, noch läßt sich umgekehrt die These halten, die Richter hätten alles

19 Coing s Mit jeder Generation komme eine neue Siche der Werte auf (Die obersten Grondsätze des Rechts, 1947, S. 33); ähnlich auch Nicolai Hartmann: $>$ Die Werterfahrung der Menschen ist begrenzt, durch seinen geschichtlichen Standort bedingt. Der Wertblidk der Menschen erfaßt jeweils nur einen Ausschnitt aus der Wertwelt und varïiert das jeweils Erschaure (Ethils 2. Aufl. 1935, 43 ff.). Zur Wandlung der Wertvorstellungen im Reche siehe insbes. Fechner, Rechtsphilosophie, 1962, S. I57 ff.

20 Gegen derartige Pauschalurteile über das Verhalten der Richter im Dritten Reich wendet sich mit scharfen Worten Weinkauff, a. 2. O., S. 179: $\rightarrow$ Die kollektiven Verdammungsurteile über die Richter wegen ihrer Haltung unter dem Nationalsozialismus sind allmählich so billig wie Brombeeren ... es sind eben Kollektivurteile und sie kümmern sich in aller Regel wenig oder gar nicht darum, zunz̈ctst einmal die Tatbestände objektiv festzustellen, an denen sioh ihre Kritik entzündet..... 
versucht, um das Unheil abzuwenden oder doch wenigstens semen umiant zu schmälern. Licht und Schatten scheinen einigermaßen gleichmäßig verteilt zu sein.

Lassen Sie mich mit einer persönlichen Bemerkung schließen. Häufig wird gefordert, man solle die Vergangenheit auf sich beruhen lassen und sich allein dem Aufbau einer besseren Zukunft widmen. Von diesem Standpunkt aus könnte es als müßige Spielerei erscheinen, Urteile aus der Zeit des Dritten Reiches zu untersuchen. Dabei wird übersehen, daß wir den Weg in die Zukunft nur dann erkennen können, wenn wir die Irrwege der Vergangenheit kennen und meiden gelernt haben, und zu diesen Irrwegen gehört teilweise auch der von der Rechtsprechung im Dritren Reich eingeschlagene $\mathbb{W e g}$. Deshalb ist es nötig, den Finger auch dann in die Wunde zu legen, wenn es schmerzt. Wo Unrecht geschehen ist, muß es als solches gekennzeichnet werden. Dabei liegr es in der Natur der Sache, daß die schuldig gewordene Generation diesen für sie schmerzlichen Prozeß nur ungern selbst einleiret, so daß es in erster Linie den jüngeren unter uns obliegt, das Notwendige zu tun. Wenn wir es tun, sollten wir jedoch nicht die Rolle des Anklägers einnehmen, sondern uns bewußt sein, daß wir dem Schicksal dankbar zu sein haben, dankbar dafür, da $B$ es uns erspart geblieben ist, in einer Zeit der Wertverneinung Recht und Unrecht scheiden und dann eine mit Nachteilen verbundene Wahl zugunsten des Rechrs treffen zu müssen. Jeder von uns sollte sich fragen, ob er für sich mir Gewißheit ausschließen kann, daß er im Dritren Reich schuldig geworden wäre. Ich glaube nicht, $\mathrm{da}$ es viele gibt, die diese Frage guten Gewissens bejahen können.

Dem Abdrudk dieses Aufsatzes ging ein Briefwechsel zwischen der Redaktion und Prof. Grunsky voraus. In einem der nächsten Hefte wird eine Kritik der Gießener Ringrorlesung $*$ Nationalsozialismus und Recht erscheinen.

\section{I}

*Auf der letzten Redaktionssitzung sind wir zu dem Entschluß gekommen, Ihren Vortrag nicht abzudrucken, wean auch ursprünglich beabsichtigt war, in der $\mathrm{KJ}$ die gesamte Vorlesungsreihe zu bringen. Dieser Entschluß beruht auf der inhaltlichen Kritik Ihres Aufsatzes, eine Kritik, die sich im wesentlichen bemessen hat an den Grundsätzen, die wir vor Erscheinen der KJ programmatisch festgelegt hatten. Darin heißr es, daß methodologische und rechtshistorische Beiträge dazu bestimmt sein sollen, Rechtswissenschaft aus ihrer selbstgewählten Isolation zu lösen und die Erkenntnisse anderer Wissenschaften wie Psychologie, Soziologie, Psychoanalyse, Wirtschaftswissenschaften für Recheswissenschaft zu vermitteln und zu verarbeiten. Diesem Anspruch schien uns Ihr methodischer Ansatz nicht zu entsprechen. Sie schreiben auf S. I 57: "Haben sie (die Ridhter) das Gesetz mit der Elle der nationalsozialistischen Weltanschauung gemessen und dadurch Ergebnisse erlangr, die wir von unserem heurigen Verständnis her ablehnen müssen, oder haben sie umgekehrt versucht, die Offenheit eines jeden Gesetzeswortlauts dazu zu verwenden, im weitest möglichen Umfang Resultate zu erreichen, die den Zielen des Nationalsozialismus widersprachen? \& Dem eatspricht es, wenn Sie später (S. I 59 ff.) die gesichteten Entscheidungen nach erfreulichen und unerfreulichen sortieren und zwischen eindeutigen Unrechtsurteilen und solchen, die auf einer Wertung des Richters beruhen, die sich jedoch nicht als Unrecht abstempeln läßr (S. 167), unterscheiden. Diese Differenzierung führt dann zu dem Satz: Dabei ist wichtig, daß innerhalb eines gewissen Rahmens keine Weltanschauung für sich in Anspruch nehmen kann, sie sei höherwertig als die andere (S. 169).* Wenn dagegen im Dritten Reich und häufig in seiner Rechtsprechung der 
Werr der Nation oder eines bodenständigen Bauerntums in einer uns nicht nachvollziehbaren Weise überbetont wird, so wird damit der Rahmen nodh nicht gesprengt. Hier bewegen wir uns im Bereich des noch Vertretbaren. * Von dieser Ihrer Wertung ist der gesamte Aufsatz folgerichtig. Wir bewegen uns dann, (die Richtigkeit unterstellt) tatsächlich auf dem Gebiete des Meinungsmäßigen, ohne rationale Kriterien für unsere so gewonnenen Ergebnisse angeben zu können. Allerdings haben Sie in Ihrer Arbeit nicht versucht nachzuweisen, daß diese Wertung notwendig ist und durch weitere Diskussion nicht zurüdk«verlegt werden kann. Dies ist nämlich nach unserer Ansicht möglich und bereits im Rahmen der Faschismusdiskussion geleistet worden. Das hat zur Voraussetzung, daß man sich über Funktion und Zielsetzung des Faschismus klar wird. Eine solche Begriffsklärung haben Sie nicht unternommen. Ihre Arbeit mußte daher notwendig personalistisch bleiben, ohne die soziale und politische Funkrion des Faschismus zu bestimmen. Ich möchte nur auf $z$ wei Veröffentlichungen hinweisen, die eine solche Analyse vermittelt haben: 1. Politische Texte 1967 bei der EVA: O. Bauer, H. Marcuse, A. Rosenberg und andere, Faschismus und Kapitalismus - Theorien über die sozialen Ursprünge und die Funktion des Faschismus; 2. Neue Wissenschaftliche Bibliothek, Verlag Kiepenheuer und Witsch, Theorien über den Faschismus, herausg. v. Ernst Nolte 1967.

Ohne eine Analyse des Faschismusbegriffs muß auch eine Analyse der Rspr. unbefriedigend bleiben und sich auf Feststellungen zurüdzziehen, die sicherlich richtig sind (S. 170), die aber Rechtswissenschaft nicht weiter bringen können. Persönliche Bekenntnisse verstellen nur eine exakte Analyse der dem Richter offenstebenden Handlungsspielräume und die Art und Weise ihrer Ausfüllung. Gerade diese Vorverständnisse an Hand der Entscheidungen herauszuarbeiten und auf ihre Herkunt zu untersuchen, wäre notwendig gewesen. Hier liegt dann auch ein Ansatz, juristisches Arbeiten in Zukunft rationaler zu gestalten und von der Beschränkung der Argumentation mit Autoritäten zu befreien. Nur dann, wenn dem Studenten die Möglichkeit vermittelt wird, die Funktion von Recht in der Gesellschaft zu verstehen, kann er auch gesellschaftliche, soziale und polirische Bedingungen in die Diskussion zur Entscheidungsfindung einbeziehen, nur dann bleibt er nicht blind gegenüber der Gebundenheit des Rechts. Es wäre die Frage zu beanrworten, warum die historisch bedingten Methoden der Rechtsfindung, die dem Richter im Faschismus zur Verfügung standen, auch heute noch sh. M.r sind, obwohl sie jedenfalls die 'Rechtsıperversion während des Dritten Reiches nicht verhindern konnten. Diese Komplexe hätten problematisiert werden müssen, um dem Juristen (wenigstens dem, der noch in der Ausbildung ist) ein Problembewußrsein überhaupt erst zu vermitteln.\&

\section{II}

- Zur Sache selbst darf ich sagen, daß mit Ihrer Zeitschrift eine eindeutige Abmachung des Inhalts getroffen worden ist, daß alle Vorträge abgedrudkt werden. Irgend eine Einschränkung bezüglich der von dem Auror zu vertretenden Auffassung ist nicht vereinbart worden und wäre von mir auch niemals akzeptiert worden. Nur unter dieser Voraussetzung war es möglich, sämrliche Autoren für eine Publizierung bei Ihnen zu gewinnen. $\mathrm{DaB}$ es bei dieser Sachlage nicht angeht, nachträglich Ihnen nicht genehme Ansichten zurüdszuweisen, liegr auf der Hand.

Sie wenden sich in erster Linie deshalb gegen meinen Vortrag, weil Sie meinen, er bewege sich zu sehr im rein Meinungsmäßigen und versuche nicht, die verschiedenen Weltanschauungen rational nachzuprüfen. Ich verstehe dies dahingehend, daß ich bei Nachbolung dieser rationalen Ưberprüfung zu einer $\gg$ weiter links stehenden * Weltanschauung kommen müßre. İh weiß, daß insbesondere ron Links-Intellektuellen (das ist keinesfalls abwertend gemeint) die Auffassung vertreten wird, ihre Auffassungen beruhten auf rein verstandesmäßiger Bewertung der Dinge. Ich habe nie einen Hehl daraus gemacht, daß ich diese Auffassung nicht zu teilen vermag. Im Laufe der Geschichte ist mit derartigen Erwägungen so viel Unheil angerichtet worden, $\mathrm{da} B$ ich gegen die Allmacht der Rationalität höchst skeptisch bin. Ich befürchte, Sie suchen hier nach der berühmten blauen Blume, die bekanntlich niemals gefunden worden ist. Dieses Suchen ist selbst- 
verständlich Ihr gutes Recht, das Ihnen von niemandem bestritten werden soil, nur meine ich, Sie können nicht verlangen, daß alle Welt mitsucht.

In engem Zusammenhang mit dem eben Gesagten steht der folgende Punkt. Sie monieren, ich härte mich nicht mit den politischen und sozialen Funkrionen des Faschismus auseinandergesetzt und es unterlassen, eine Begriffsbestimmung des Faschismus zu geben. Ich stimme darin zu, daß ein Vortrag wie der meine voraussetzt, daß der Zuhörer über Grundzüge dessen, was im Dritten Reich bei uns geschehen ist, Bescheid weiß. Diese erforderlichen Grundkenntnisse glaubte ich voraussetzen zu dürfen. Andrerseits meine $\mathrm{ich}, \mathrm{da} ß$ sie für eine Bewertung der Rechtsprechung ausreichen. Eine Begriffsbestimmung des Faschismus konnte ich schon deshalb nicht geben, weil ich dazu entweder Politologe oder Historiker sein müßre. Darüberhinaus meine ich, daß der Faschismusbegriff zumindest in dem heute gebrauchten Sinne so umfassend ist, daß er für mich nurmehr eine sehr geringe Aussagekraft besitzt. Politische Zustände in Spanien und das bei uns von 1933-1945 herrschende Regime sind so unterschiedlich, daß man in meinen Augen den Dingen Gewalt antut, wenn man glaubr, sie unter einen gemeinsamen Oberbegriff fassen zu können. Damit verkenne ich selbstverständlich nicht, daß beide Länder gewisse Gemeinsamkeiten aufweisen. Idh weiß nicht, ob ich Sie richtig verstehe, wenn ich Ihre Kritik an der fehlenden Analyse des Faschismusbegriffs dahingehend auffasse, daß ich bei Vornahme dieser Analyse zu dem Ergebnis gekommen wäre, der Faschismus habe die von mir als vertretbar bezeichnete Auffassung über den Wert der Nation oder eines bodenständigen Bauerntums stark in den Vordergrund gerückt, und daß diese Meinung deshalb für uns eindeutig unrichtig sein muß. Sollte dieses Verständnis Ihrer Kritik richtig sein, so muß ich dazu sagen, daß sich für mich dahinter eine unbefriedigende $\gg$ AntiHaltung * verbirgt, die mir dem bei uns häufig gepflegten Anti-Kommunismus zu entsprechen scheint. Eine Idee ist nicht deshalb schlecht und wird nicht deshalb unvertretbar, weil sie von einem Regime propagiert wird, daß sie mißbraucht oder neben ihr andere, unvertretbare Auffassungen befürwortet. Die bloße Herkunft eines Gedankens sagt über seinen Wert oder Unwert nichts aus. Um Mißverständnissen vorzubeugen, darf ich hinzufügen, da $B$ ich ein Gegner sowohl des angeblichen Wertes der Nation als auch des bodenständigen Bauerntums (so wie dieser Begriff im Drirten Reich verstanden worden ist) bin. Ich wende mich nur dagegen, diese meine Auffassung sei rational nachrollziehbar und jeder, der anderer Ansicht ist, zeige damit, daß er unrecht hat. Ich würde mich freuen, wenn ich Sie in diesem Punkt falsch verstanden habe. Idh möchte Sie bitten, in diesem Fall meine Bemerkungen zu übersehen.

Erlauben Sie mir schließlich noch ein kurzes Wort zur juristischen Methodenlehre, auf die Sie ja ebenfalls Bezug nehmen. Sie tügen, daß wir noch heute mit denselben Methoden arbeiten, die im Drirten Reich nicht in der Lage waren, das Unheil zu verhindern, ja es stellenweise sogar vergrößert haben. Dieser Ihr Befund ist sicher richtig, doch meine ich, $\mathrm{da}$ sich auch hier Ihr Streben nach etwas finder, das es nicht gibe. Die juristische Methodenlehre ist weitestgehend wertneutral. Sie bedeutet unser berufliches Handwerkszeug, und wie bei jedem Handwerkszeug ist die Frage, in wessen Hände es gerät. Mit einem Hammer können Sie sehr nützliche Dinge herstellen, Sie können damit aber auch einem Menschen den Schädel einschlagen. Uber den Wert des Hammers läßr sich weder bei der einen noch bei der anderen Anwendung etwas sagen. Ober die notwendigerweise gegebene Wertneutralitär der Methodenlehre darf ich insbesondere auf die ausführlichen Hinweise in dem Buch von Rüthers hinweisen, das Sie sicherlich kennen. Ich habe ihnen nichts hinzuzufügen. \& 